\title{
Thermal behavior of lead silicate vitreous materials for sealants
}

\author{
Ana-Maria Mocioiu ${ }^{1}$ and Oana Cătălina Mocioiu ${ }^{2, *}$ \\ ${ }^{1}$ National Research and Development Institute for Non-Ferrous and Rare Metals -IMNR, 102 Biruintei Blvd., Pantelimon, \\ JudIlfov 077145, Romania \\ 2 Ilie Murgulescu Institute of Physical Chemistry of the Romanian Academy, 202 Splaiul Independenţei, Bucharest 060021, \\ Romania
}

Received: 2 November 2020 / Accepted: 15 January 2021

\begin{abstract}
The objective of our investigations consists in the thermal characterization of $\mathrm{SiO}_{2}-\mathrm{PbO}-\mathrm{Na}_{2} \mathrm{O}$ vitreous materials in order to establish their properties for applications mainly as sealants. In order to evaluate the vitreous material - metal adherence, the thermal expansion coefficients $(\alpha)$ from experimental and theoretic data were determined. The differential thermal analysis of studied materials give the information about temperatures characteristic to glass transition, crystallization and melting. Dilatometer measurements were performed in air atmosphere in order to establish thermal coefficients of the materials. Softening and flowing characteristic of the vitreous materials were established by heating microscope measurements. The difference between thermal expansion coefficient $(\alpha)$ of the vitreous materials $\left(10.2 \times 10^{-6} \mathrm{~K}^{-1}\right.$ and $\left.17.6 \times 10^{-6} \mathrm{~K}^{-1}\right)$ and thermal expansion coefficient of the steel substrate OL $38\left(10.8 \times 10^{-6} \mathrm{~K}^{-1}\right)$ is under $37 \%$. This value is fit for a good adherence between materials.
\end{abstract}

Keywords: Softening temperature / the flow point / thermal expansion coefficients

\section{Introduction}

Modern technologies such as additive manufacturing, and products as fuel cells (SOFC) and batteries, are new challenges for study of the expansion coefficients and thermal properties of the materials [1-7]. Looking from this perspective the problematic of the paper begin to renew in agreement with their demands. Vitreous materials can be useable as high temperature sealant (like SOFC) [1-3]. Adherence, or bonding, of vitreous material to metal is extremely important in producing of thedental restorations, seals, photonic crystal fibers and protective coatings on metals [1-9]. A parabolic trough solar receiver is one of the most important elements in the solar thermal power system for converting the solar energy into thermal energy. The receiver typically consists of a metal pipe with a solar selective coating and a glass tube for evacuation [2]. The failure of the glass-to-metal seal has a significant impact on the thermal performance of the receiver $[2,3]$. It can cause vacuum loss, fracture of glass tube and solar selective coating degradation [2].

The series of $\mathrm{SiO}_{2}-\mathrm{Bi}_{2} \mathrm{O}_{3}-\mathrm{PbO}-\mathrm{ZnO}-\mathrm{BaO}$ and $\mathrm{SiO}_{2}$ $\mathrm{TiO}_{2}-\mathrm{Bi}_{2} \mathrm{O}_{3}-\mathrm{PbO}-\mathrm{Na}_{2} \mathrm{O}$ vitreous materials were synthetized dedicated to fabrication of photonic crystal fibers [8].

\footnotetext{
* e-mail: oana.mocioiu@yahoo.com
}

During composition development, the thermal properties were investigated according to the change of chemical composition [8]. The high concentrations of heavy metal oxides improve nonlinear refractive index and spectrally broad transmission window from 0.5 to $4.5 \mathrm{~mm}$ [8]. Their thermal properties are optimized to enable drawing of allsolid photonic crystal fibers [8].

The objective of our investigations consists in the thermal characterization of lead silicate vitreous materials in order to establish their properties forsealing applications. In order to evaluate the materials - steel adherence, the thermal expansion coefficients $(\alpha)$ from experimental and theoretic data were established. The vitreous oxide materials are called hard when $\alpha$ is lower than $6 \times 10^{-6} \mathrm{~K}^{-1}$ and they are called soft when $\alpha$ is higher than $6 \times 10^{-6} \mathrm{~K}^{-1}$. Vitreous silica has a very low thermal expansion coefficient value of $0.5 \times 10^{-6} \mathrm{~K}^{-1}$.

\section{Experimental methods}

The $\mathrm{SiO}_{2}-\mathrm{PbO}-\mathrm{Na}_{2} \mathrm{O}$ vitreous materials were prepared by traditional route. Starting materials were $\mathrm{SiO}_{2}, \mathrm{PbO}$ and $\mathrm{Na}_{2} \mathrm{CO}_{3}$ (p.a. Merck). The melting of starting materials mixturein appropriate compositions was made at $1400^{\circ} \mathrm{C}$ for $1 \mathrm{~h}$ into electrical oven. The vitreous oxide materials were cast in carbon mold and thermally treated at $300^{\circ} \mathrm{C}$ 
Table 1. Chemical composition of the studied vitreous oxide materials.

\begin{tabular}{llll}
\hline Material & \multicolumn{3}{c}{ Oxide composition $(\% \mathrm{~mol})$} \\
\cline { 2 - 4 } & $\mathrm{SiO}_{2}$ & $\mathrm{PbO}$ & $\mathrm{Na}_{2} \mathrm{O}$ \\
\hline $\mathrm{A} 2$ & 50.0 & 15.4 & 34.6 \\
$\mathrm{~A} 3$ & 52.0 & 18.0 & 30.0 \\
$\mathrm{~A} 5$ & 54.0 & 20.7 & 25.3 \\
\hline
\end{tabular}

for $2 \mathrm{~h}$. Thermal treatment lead to relaxation of structure and elimination of stress that can break the material. Oxide composition for obtained vitreous materials is presented in Table 1.

The differential thermal analysis curves were recorded in range $20-900{ }^{\circ} \mathrm{C}$, with a heating rate $10^{\circ} \mathrm{C} / \mathrm{min}$, with a Setaram apparatus. Dilatometer measurements were performed in air atmosphere on Linseis apparatus model L75. Sintering characteristics, softening characteristics, and melting characteristics were measured using a Carl Zeiss Jena heating microscope between $20-1000^{\circ} \mathrm{C}$. All components of the heating microscope (the lamp, furnace and camera) are arranged on an optical bench for exact alignment. The silhouettes of a test object are analyzed, while it is being heated in a small tube furnace. The morphology of the vitreous oxide materials were investigated by scanning electron microscopy (SEM) using a microscope, Quanta FEI 250 model, at an accelerating voltage of $10 \mathrm{kV}$. Sample preparation was minimal and consisted in immobilizing the samples on a double-sided carbon tape, with no coating.

\section{Results and discussions}

The system $\mathrm{SiO}_{2}-\mathrm{PbO}-\mathrm{Na}_{2} \mathrm{O}$ was studied from structural point of view in previously published articles [10-12]. The oxide composition have different structure, morphologies and properties due to existence of six subsystems in the phase diagram of the ternary system. The presence of vitreous or crystalline state in obtained materials is lead by Gibbs free energy [10-12]. Thermal analysis measurements shown in previous article [12] evidenced increase of temperature $\mathrm{Tg}$ with lead contend in composition. The same behavior can be seen below in the dilatometer measurements.

In the Table 2 are presented results of heating microscope measurements. Carl Zeiss Jena heating microscope used to investigate thermal behavior of materials have three principal components: lamp, furnace and camera. All components of the heating microscope are arranged on an optical bench that ensures exact alignment which is essential for precise image analysis. The increasing of the temperature in the oven is controlled by a thermocouple located directly below the sample. The protection of the thermocouple against mechanical damage, influences from the furnace atmosphere and contamination by the sample is made by a sintered alumina plate. Another distinctive element of the heating microscope is its
Table 2. Results of heating temperature microscopy.

\begin{tabular}{llll}
\hline Material & $\begin{array}{l}\text { Softening } \\
\text { temperature } \\
\left({ }^{\circ} \mathrm{C}\right)\end{array}$ & $\begin{array}{l}\text { Half-ball } \\
\text { temperature } \\
\left({ }^{\circ} \mathrm{C}\right)\end{array}$ & $\begin{array}{l}\text { Flow } \\
\text { temperature } \\
\left({ }^{\circ} \mathrm{C}\right)\end{array}$ \\
\hline A2 & 780 & 800 & 840 \\
A3 & 470 & 580 & 670 \\
A5 & 460 & 600 & 700 \\
\hline
\end{tabular}

Table 3. Characteristic temperatures obtained from dilatometer measurements.

\begin{tabular}{llll}
\hline Material & $\operatorname{Tg}\left({ }^{\circ} \mathrm{C}\right)$ & $\operatorname{Tsr}\left({ }^{\circ} \mathrm{C}\right)$ & $\operatorname{Td}\left({ }^{\circ} \mathrm{C}\right)$ \\
\hline A2 & 420 & 432 & 454 \\
A3 & 407 & 415 & 429 \\
A5 & 348 & 357 & 368 \\
\hline
\end{tabular}

specimen carriage, which is moved on rails that are rigidly attached to the furnace carrier. This enables you to position a sample on the alumina plate outside the (hot) furnace and then to move them in a desired position inside. At the same time, the furnace is sealed off. The analyses can be carried out on one sample at the time, to identify characteristic temperatures as: Softening, Half ball and Flow. The temperature is correlated with changes in dimension and shape of thesample. The formation of halfball and flow of melting show a good wettability of substrate with studied materials. The wettability and flow behavior of the seals could be adjusted by controlling the temperature. The adhesion of the oxide materials show that they can be used as seals. The difference from the obtained temperatures show the process-ability of the vitreous oxide material. Oxide material noted A2 flow at the highest temperature and has the lowest interval $\left(60^{\circ} \mathrm{C}\right)$. Materials noted $\mathrm{A} 3$ and $\mathrm{A} 5$ melt and flow to substantially lower temperatures and have a much higher melting interval $\left(200^{\circ} \mathrm{C}\right.$ for $\mathrm{A} 3$, and $240^{\circ} \mathrm{C}$ for $\mathrm{A} 5$, respectively). Vitreous material noted A5 presents the appropriate properties for applications.

Table 3 show characteristic temperatures obtained from dilatometer measurements: transition temperature $(\mathrm{Tg})$, structure relaxation temperature (Tsr), and softening point $(\mathrm{Td})$.

Any of them give important information used in industrial applications. Glass transition temperature $(\mathrm{Tg})$ is the temperature in the glass transition region where the metastable melt transforms into glass in the course of its cooling and where glass transforms into metastable melt in the course of heating. The structure relaxation temperature (Tsr) is temperature used for thermal treatment of glasses for ordering of structural units without softening of the material. This is important to prevent cracks in glass. The difference between $\mathrm{Tg}$ and $\mathrm{Td}$ values can be correlated with viscosity of glass and influence on the workability. For example in borosilicate glasses the phase separation process leads generally to the 
Table 4. The thermal expansion coefficient obtained by theoretical and experimental mode.

\begin{tabular}{lll}
\hline Material & $\begin{array}{l}\alpha \text { calculated } \\
\text { with Appen } \\
\text { formula }[1 / \mathrm{K}]\end{array}$ & $\begin{array}{l}\alpha \text { measured with } \\
\text { dilatometer } \\
{[1 / \mathrm{K}]}\end{array}$ \\
\hline A2 & $17.96 \times 10^{-6}$ & $17.6 \times 10^{-6}$ \\
A3 & $18.13 \times 10^{-6}$ & $13.4 \times 10^{-6}$ \\
A5 & $18.32 \times 10^{-6}$ & $14.2 \times 10^{-6}$ \\
\hline
\end{tabular}

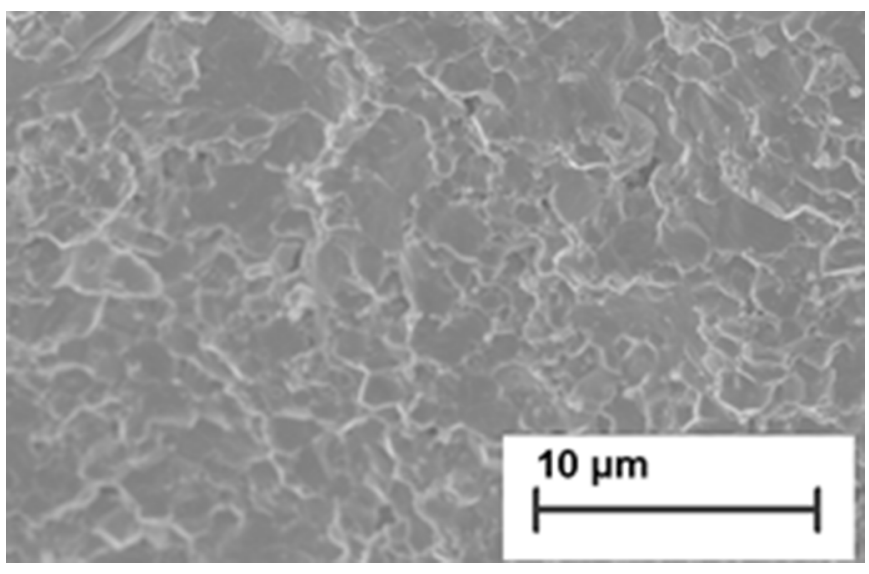

Fig. 1. SEM image of material noted A2.

Table 5. The influence of the thermal expansion coefficient on the adhesion from literature data $[2,5]$.

\begin{tabular}{|c|c|c|c|c|}
\hline CTE glass & CTE metal & Difference & Adhesion & Reference \\
\hline $\begin{array}{l}\text { Pyrex glass } \\
3.3 \times 10^{-6} / \mathrm{K}\end{array}$ & $\begin{array}{l}\text { stainless steel } 304 \\
10.2 \times 10^{-6} / \mathrm{K}\end{array}$ & $67 \%$ & Breakage & {$[2]$} \\
\hline $\begin{array}{l}\text { Pyrex glass } \\
3.3 \times 10^{-6} / \mathrm{K}\end{array}$ & $\begin{array}{l}\text { stainless steel } 430 \\
12 \times 10^{-6} / \mathrm{K}\end{array}$ & $85 \%$ & Breakage & {$[2]$} \\
\hline $\begin{array}{l}\text { Pyrex glass } \\
3.3 \times 10^{-6} / \mathrm{K}\end{array}$ & $\begin{array}{l}\text { Kovar } \\
6.15 \times 10^{-6} / \mathrm{K}\end{array}$ & $46 \%$ & Partial good & {$[2]$} \\
\hline $\begin{array}{l}5.0 \text { borosilicate glass } \\
5.5 \times 10^{-6} / \mathrm{K}\end{array}$ & $\begin{array}{l}\text { Kovar } \\
6.15 \times 10^{-6} / \mathrm{K}\end{array}$ & $10.5 \%$ & Good & {$[2,5]$} \\
\hline
\end{tabular}

formation of at least two vitreous phases, one silica rich phase and a borate rich phase [13]. The lower viscosity phase controls mainly the value of $\mathrm{Tg}$ while the connectivity of the high viscosity silica rich phase determines the value of $\mathrm{Td}$ [13]. To obtain suitable wettability and bonding strength, the seals were heated above Td [3]. The lower temperatures are present in vitreous material noted $\mathrm{A} 5$ and the highest are characteristic to A2.

Table 4 exhibits calculated thermal expansion coefficient of the studied vitreous oxide materials. Calculus of thermal expansion coefficient can be obtained starting from oxide composition or dilatometer measurements. The thermal expansion coefficients of the studied materials was calculated starting from composition according to Appen formula (Eq. (1)).

$$
\alpha=\frac{\sum_{1}^{i} m_{i} \cdot \alpha_{i}}{100}
$$

where $m_{i}$ represents the fraction of the initial oxides expressed in molar fraction; $\alpha_{i}$-the characteristic parameters of the initial oxides.

The calculated thermal coefficients increase with content of lead oxide in the glass. The coefficient measured from room temperature to $800{ }^{\circ} \mathrm{C}$, are smaller than the calculated data probably due to volatilization of a small content of lead oxide. The thermal expansion coefficient of the OL 38 steel substrate $\alpha=10.8 \times 10^{-6} \mathrm{~K}^{-1}$. The difference between thermal expansion coefficient of the vitreous materials and thermal expansion coefficient of the steel substrate OL 38 is under $37 \%$, the value admitted for a good adherence. The difference between thermal expansion coefficient of glass and metals is important as can be seen in the literature data exhibit in the Table 5 . The results of the investigations led to conclusion that the studied vitreous materials are adequate for use as sealant and junction with steel.

Figure 1 displays the morphology of the material noted A2. In the figure can be seen a matrix homogeneous specific to vitreous state.

\section{Conclusions}

Vitreous oxide materials in the $\mathrm{SiO}_{2}-\mathrm{PbO}-\mathrm{Na}_{2} \mathrm{O}$ systems were investigated from point of view of thermal properties. The heating microscope measurements show the possibility to obtain good adherence of materials on steel. The melting interval of the materials depend on the composition. The dilatometer characteristic temperatures present the same behavior. The calculated thermal coefficients increase with content of lead oxide in the materials. The measured coefficients are smaller than the calculated data probably due to volatilization of a part of lead content. The difference between thermal expansion coefficient of the 
vitreous materials and thermal expansion coefficient of the steel substrate OL $38\left(10.8 \times 10^{-6} \mathrm{~K}^{-1}\right)$ is under $37 \%$, the value admitted for a good adherence. The results of the investigations led to conclusion that the studied vitreous materials are adequate for use as sealant and junction with steel.

This paper was presented at the 3rd International Conference "Emerging Technologies in Materials Engineering EmergeMAT", organized by the National R\&D Institute for Non-ferrous and Rare Metals - IMNR, Romania, 29-30 October 2020.

\section{References}

1. M. Garai, B. Karmakar, S. Roy, Front. Mater. 7 (2020) 57

2. D.Q. Lei, Z.F. Wang, Z.J. Wang, Energy Procedia 49 (2014) 418

3. R. Li, L. Peng, X. Wang, J. Yang, D. Yan, J. Pu, B. Chi, J. Li, Compos. B 192 (2020) 107984
4. R.L. Dumitrache, I. Teoreanu, UPB Sci. Bull. Series B, 68 (2006) 3

5. D. Lei, Z. Wang, J. Li, J. Li, Z. Wang, Renew. Energy 48 (2012) 85

6. J. Fang, L. Sun, S. Guo, C. Liu, J. Zhang, J. Euro. Ceram. Soc. (2020)

7. S. Li, K. Hu, W. Hui, Y. Cai, Y. Zhang, J. Alloys Compd. 827 (2020) 154275

8. R.K. Guntu, Mater. Sci. Eng. B 262 (2020) 114784

9. S. Memon, P.C. Eames, Energy Build. 227 (2020) 110430

10. O.C. Mocioiu, A.M. Mocioiu, A. Marin, M. Zaharescu, Ceram. Int. 43 (2017) 77

11. O.C. Mocioiu, M. Popa, E.I. Neacsu, M. Zaharescu, J. Non Cryst. Solids 361 (2013) 130

12. O.C. Mocioiu, M. Zaharescu, I. Atkinson, A.M. Mocioiu, P. Budrugeac, J. Therm. Anal. Cal. 117 (2014) 131

13. M.J. Pascual, A. Durán, L. Pascual, Phys. Chem. Glasses 43 (2002) 25

Cite this article as: Ana-Maria Mocioiu, Oana Cătălina Mocioiu, Thermal behavior of lead silicate vitreous materials for sealants, Manufacturing Rev. 8, 4 (2021) 